\title{
Controle social e governo de dados
}

\author{
Augusto Jobim do Amaral ${ }^{1}$ \\ Felipe da Veiga Dias ${ }^{2}$ \\ http://orcid.org/0000-0003-0874-0583 \\ http://orcid.org/0000-0001-8603-054X \\ ${ }^{1}$ Pontifícia Universidade Católica do Rio Grande do Sul, Departamento de Direito, Programa de Pós-Graduação em Ciências Criminais, \\ Porto Alegre, RS, Brasil \\ ${ }^{2}$ Faculdade Meridional, Departamento de Direito, Programa de Pós-Graduação em Direito, Passo Fundo, RS, Brasil
}

\section{Controle social e governo de dados}

Resumo: $\mathrm{O}$ artigo tem como temas o controle e a biopolítica, tendo a sua delimitação nas questões tecnológicas como parte das relações de controle biopolítico e na afetação local. O problema de pesquisa é: de que forma o atual projeto biopolítico de controle neoliberal afeta a sociedade brasileira enquanto uma democracia recente e quais as peculiaridades podem ser percebidas? Dito isso, utiliza-se como metodologia a abordagem fenomenológico-hermenêutica, juntamente aos métodos de procedimento monográfico e a técnica de pesquisa por documentação indireta. Conclui-se que o projeto biopolítico nacional baseia-se na lógica neoliberal, e por isso se impõe de forma a exigir o máximo da vida humana em prol da lucratividade, enquanto aumenta cada vez mais a amplitude dos dispositivos de controle (e disciplina, reservada aos inaptos), ao mesmo tempo em que no País se verifica certa radicalidade de caraterísticas autoritárias e conflitivas na adoção do modelo de controle contemporâneo na democracia nacional.

Palavras-chave: Biopolítica. Sociedade do Controle. Dados. Democracia.

\section{Social control and data governance}

Abstract: The research has as its themes control and biopolitics, having its delimitation in technological questions as part of the relations of biopolitical control, and in the local affectation. The research problem is: how does the current biopolitical project of neoliberal control affect Brazilian society as a recent democracy and what peculiarities can be perceived? That said, the phenomenologicalhermeneutic approach is used as a methodology, together with the monographic procedure methods and the indirect documentation search technique. It is concluded that the national biopolitical project is based on neoliberal logic, and therefore imposes itself in such a way as to demand the maximum of human life for profitability, while increasing the breadth of control devices (and discipline, reserved), at the same time that in the country there is a certain radicality of authoritarian and conflicting characteristics in the adoption of the contemporary control model in national democracy.

Keywords: Biopolitics. Control Society. Data. Democracy.

Recebido em 11.08.2019. Aprovado em 11.02.2020. Revisado em 13.04.2020.

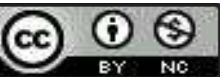

(C) O(s) Autor(es). 2020 Acesso Aberto Esta obra está licenciada sob os termos da Licença Creative Commons Atribuição-NãoComercial 4.0 Internacional (https://creativecommons.org/licenses/by-nc/4.0/deed.pt_BR), que permite copiar, distribuir e reproduzir em qualquer meio, bem como adaptar, transformar e criar a partir deste material, desde que para fins não comerciais e que você forneça o devido crédito aos autores e a fonte, insira um link para a Licença Creative Commons e indique se mudanças foram feitas. 


\section{Introdução}

O estudo em tela parte do tema do controle e da biopolítica como elementos centrais de observação. Essa proposição ampara-se na tentativa de compreensão, dentro das dinâmicas das relações de poder e da produção de subjetividades, das estratégias que se implementam atualmente em termos de gerenciamento da vida.

Assim, a fim de delimitar ainda mais o escopo da pesquisa, direciona-se a atenção à sociedade do controle, mormente desde os dados/metadados obtidos e fornecidos pelos dispositivos tecnológicos hodiernos. Opta-se por tal espectro em razão das performances das relações humanas em termos neoliberais - de otimização pessoal e de necessidade de exposição, muito para além das práticas disciplinares rígidas -, exercidas através da voluntariedade e do uso intensivo da liberdade, em que todos, de algum modo, geram para Estados e empresas informações sobre sua existência.

Significa dizer que há um novo espectro biopolítico em operação, que amplia os dispositivos de controle, a seu modo, alimentados pela própria população e produtora de enorme capital imaterial através das plataformas tecnológicas, satisfazendo um modo de vida em que a empresa se torna o modo de subjetivação por excelência, ao mesmo tempo em que as patologias sociais governam as populações até a sua exaustão física-mental.

Diante desse contexto, é importante frisar que as práticas de soberania clássicas ou mesmo disciplinares do alvorecer da modernidade de modo algum tornaram-se superadas ou desapareceram. A seu modo, foram repotencializadas e mantêm-se plenamente aplicáveis aos inaptos dos processos tecnológicos deste estágio do capitalismo. Daí surge um enfoque especial a respeito de como tais processos afetam, no plano nacional, os parâmetros democráticos.

Assim, tem-se como problema de pesquisa de que forma a atual dinâmica biopolítica, exercida através do modo de vida neoliberal, afeta de modo particular a sociedade brasileira enquanto uma democracia recente e quais as peculiaridades podem ser percebidas. A fim de concretizar repostas a tais indagações, utiliza-se como metodologia a abordagem fenomenológico-hermenêutica, valorando os elementos utilizados por sua inserção contextual. Juntamente a essa perspectiva estão os métodos de procedimento monográfico e a técnica de pesquisa por documentação indireta, com ênfase em bases bibliográficas e pesquisas empíricas.

\section{Biopolítica e sociedade do controle no capitalismo contemporâneo}

No transcurso final do último século até hoje o discurso da transformação do mundo por meio da tecnologia apenas se intensificou, denotando que a arte de governar teria em suas mãos modos diferenciados de operar. Esses mecanismos inovadores e aceitos naturalmente pela população tratam de pulverizar os limites entre Estados e mercados, resultando na ampliação da vigilância e controle, juntamente a algo que se encontra na origem da gestão do governo: a economia, já que "a arte de governar é, precisamente, a arte de exercer o poder na forma e segundo o modelo da economia" (FOUCAULT, 2008, p. 127).

O modelo neoliberal que torna indistinguível a gestão da vida por entes públicos ou privados apresenta a tecnologia como uma fonte neutra na condução e gestão de pessoas. Porém, ao mesmo tempo, conduz os ganhos ao bom e velho modo capitalista de mercantilizar todo e qualquer aspecto humano em sociedade. "Esse poder de condicionar corpos e almas se manifesta como biopoder, através de funções de administração e de controle sobre os corpos, mais precisamente dirigindo e canalizando a população para fins neoliberais, e como psicopoder", produzindo intervenções até mesmo no campo psíquico, "o que permite somar o controle externo (e a respectiva exploração-do-outro), produzido pelo poder punitivo, ao autocontrole e à autoexploração (exploração-de-si), promovidos pelo psicopoder" (CASARA, 2018, p. 49).

Contudo, para otimizar os objetivos desse novo capitalismo tecnológico é necessária uma política que gerencie a vida e, simultaneamente, a submeta ao seu controle, ou seja, impõe-se uma biopolítica que realize a gestão potencializando a vida ao mesmo tempo em que exerce sobre ela o bipoder que a mantenha sob seus comandos (ESPOSITO, 2006, p. 26). Isso significa que pensar o período atual requer o entendimento de que a visão econômica dominante (e o próprio modelo social correlato) opera segundo parâmetros de uma sociedade do controle, onde se mesclam os instrumentos de controle realizados ao ar livre, não meramente mais apenas segundo a tônica disciplinar-institucional dos corpos (DELEUZE, 1992, p. 220).

Demonstrações de ferramentas tecnológicas a serviço do controle vão desde dispositivos de segurança comuns, tais como câmeras de vigilância, reconhecimento facial ou rastreamento de veículos (GPS), até ações aparentemente simples como registro de trajetos de corrida, preferência de compra online, desbloqueio de smartphones através da inserção de digitais (biometria) ou de verificação da íris dos olhos. Tais dispositivos produzem informações e conteúdos valiosos para montagem das estratégias na sociedade de controle. 
Salutar inferir que, como explica Chignola (2018, p. 241), essa modificação de atuação disciplinar para a de controle era também uma necessidade do modelo capitalista, a fim de incrementar a acumulação humana e do capital na extração da mais-valia. Nesse sentido, se poderia compreender essa necessidade de organizar a força de trabalho como instrumento, seja por Estados ou corporações, a fim de auferir a atuação biopolítica como forma de modificar o exercício do poder sobre o corpo para um conjunto de técnicas/táticas de organização e vigilância sobre essa mesma força em prol dos rumos neoliberais (REVEL, 2014, p. 148).

Logo, há busca por corpos úteis e, por isso, agora vigiados para tal utilidade, ou seja, a destruição dos corpos passa a ser contraproducente na geração de riqueza, por isso a mudança no exercício do poder e, por conseguinte, a formação de uma biopolítica que possibilite essa exploração (REVEL, 2014, p. 148). Compreende-se assim a ligação entre os elementos biológico e político que formam esta rede, haja vista que a vida precisa ser a todo tempo controlada para atingir os fins pretendidos pelos pressupostos políticos do capitalismo tecnológico. Dessa forma, o capitalismo tecnológico tem neste modo biopolítico de agir uma pressuposição básica, visto que para governar deve-se "estruturar o eventual campo de ação dos outros" (FOUCAULT, 1995, p. 244), utilizando-se instrumentos tecnológicos que fornecem a previsibilidade necessária para tanto.

Todavia, esse estímulo à produção da vida incitado pela suposta liberdade suga a energia vital ao máximo com o objetivo de aprimorar os ganhos econômicos segundo os ditames neoliberais da concorrência permanente. Sem que exista qualquer surpresa nessa biopolítica suicida (ao menos para os seres humanos), é ela exatamente que se encontra em operação no capitalismo tecnológico, que impõe o desempenho maximizado e constante como padrão (irreal) a ser seguido.

Portanto, o empresário de si mesmo é o sujeito neoliberal desejado, embora esgotado e doente, mas imperioso ao incremento econômico (HAN, 2015, p. 23-27). Esse sujeito definido como uma empresa individual "através de uma nova semântica, não é apenas um esquema teórico, mas a prática real de um novo direito do trabalho através do desmantelamento das instituições neoliberais de welfare e dos direitos sociais" - aspecto que tinha no Estado o grande assegurador coletivo e que agora passa a gerir/treinar o sujeito para essa nova forma de liberdade nos moldes neoliberais: "o capital humano deve ser formado. E para isto é necessária a intervenção constante do governo" (CHIGNOLA, 2015, p. 16).

Com base nisso, é ocultada a subserviência governamental às demandas econômicas da era digital, bem como seus efeitos sobre os indivíduos que se expandem, por exemplo, em cidades inteligentes, através de "empresas [que] devem ser disruptivas, os trabalhadores devem se tornar flexíveis e os governos devem ser enxutos e inteligentes. Nesse ambiente, quem trabalha muito pode aproveitar as mudanças e vencer. Ou assim nos disseram" (SRNICEK, 2017, p. 11, tradução nossa).

As promessas de progresso que escondem os danos produzidos são uma marca do capitalismo tecnológico neoliberal, que investe em controle focado na liberdade enganosa e nas falácias da individualidade que alimentam voluntariamente um sistema moldado para prever comportamentos e estimular consumo, enquanto enclausura subjetividades (HONESKO, 2018, p. 32). Ademais, soma-se a isso o fato de que se impõe a cultura de empreender constantemente, reinventando a si mesmo pelo mercado, de modo a responder ao cenário de crise com inovação e criatividade. Contudo, isso novamente esconde o fato de que se a crise é constante, funcional e opera organicamente na geração de lucros, não se trata mais de algo negativo (CASARA, 2018, p. 12), e sim de retórica a serviço da máquina biopolítica neoliberal, a qual gera problemas, danos e prejuízos sociais.

A ilusão criada pelo modelo capitalista digital encontra-se também em sua força discursiva. Plausível evidenciar que a terminologia utilizada nos debates digitais é não despropositada, propriamente para imunizá-la de qualquer crítica; pois, afinal, quem poderia se opor à informação ou à tecnologia, as quais transmitem a ideia de conhecimento e progresso? Inserir argumentos envoltos nesta gramática busca afastar reflexões econômicas ou políticas, para com isso não demonstrar o quanto tais fatores estão profundamente associados. Pensar em qualquer manejo na regulação de dados é atingir diretamente, por exemplo, a Google e sua economia imaterial de armazenamento e comércio desses dados, visto este movimento como um empecilho ao progresso (MOROZOV, 2018, p. 29).

Algumas situações práticas exemplificam as manipulações e obscuridades em determinadas proposições. Basta pensar em aplicativos (produzidos por muitas startups para alavancar negócios digitais) que prometem um estilo de vida mais saudável ou o aumento da economia da família de baixa renda, como os exemplos: a) BillGuard, que não apenas informa o indivíduo que ele ultrapassou os gastos mensais, como igualmente pesquisa online descontos em cupons para redução das despesas; b) ou ainda o caso do iBag que se constitui em uma bolsa com sensores que se fecha (com a carteira do seu usuário dentro) para impedir os excessos de seu possuidor; c) por fim, na área da saúde cita-se o aplicativo Glow, o qual rastreia as atividades sexuais das mulheres, ciclo menstrual, início de ovulação, para auxiliar nas tentativas de engravidar. Em princípio, parecem orientar demandas sociais (saúde e economia familiar), mas o fazem ao preço de obter cada vez mais dados e informações sem esquecer que, por outro lado, justamente acabam por desonerar os entes 
públicos, pois diante da falha individual em gerir as indicações programadas (sempre vistos como objetivos e neutros) o responsável sempre será o sujeito e não mais o Estado diante da sua função básica em prover serviços de saúde e subsistência básica (MOROZOV, 2018, p. 107-110).

Necessário, portanto, compreender mais profundamente o funcionamento do capitalismo tecnológico posto atualmente. Ao se fazer isso, tal postura permite apontar os aspectos geopolíticos e econômicos que circundam essas empresas, especialmente no seu suposto bem comum (preços mais baixos, facilitação de serviços, etc.) que mascara as práticas neoliberais. Caso emblemático da Uber que, por exemplo, reduz custos ao não dar treinamento para motoristas atenderem pessoas com deficiência e, igualmente, a mesma empresa financiada pelo banco de investimentos Goldman Sachs, filia-se a tratados que facilitam a circulação de dados. Ora, na atual economia global em que dados são valiosíssimos, fazer circulá-los é parte da estratégia de lucratividade (MOROZOV, 2018, p. 23).

Torna-se claro que no capitalismo tecnológico ganham valia conteúdos, citados como imateriais, antes ignorados, como dados, metadados etc., os quais costumam estar associados com modelos de negócio conhecidos como plataformas (que funcionam como intermediários entre grupos distintos). Esse modelo inclui armazenamento, análise, obtenção, manipulação e diversas outras atividades que monopolizam informações ou dados que antes eram desperdiçados e que agora podem ser adotados em variados espectros (SRNICEK, 2017, p. 29), dentre eles, serviços, consumo, controle ou a vigilância (perspectivas valiosas aos governos e relativamente baratas segundo determinados modelos de negócio, ao menos para o fornecimento desses dados).

Conforme já mencionado, tal modelo de negócio sobre

[...] tecnologia e a liberdade, perfectibilizadas desde um big data, já aparece ocupando um ponto de destaque na execução dos projetos políticos neoliberais implementados no País. Todavia, nos estertores de um Estado PósDemocrático, que o Brasil dá sinais, existem os aprofundamentos autoritários gerados pela profusão falseada de discursos de ódio que reforçam dinâmicas de morte tradicionalmente exercidas. que indicam a melhor decisão (ao menos segundo o vencedor do leilão de dados), de maneira a ter a ilusão de decisão autônoma. Esse caso não é hipotético, pois as ferramentas para colocá-lo em prática já existem no Google, o que demonstra que não se está em uma discussão unicamente tecnológica, mas sim de "economia política, propaganda e autonomia", sobre o ponto de rentabilidade desse modelo: os dados (MOROZOV, 2018, p. 33).

As plataformas como Google, Amazon, Apple, Facebook, Uber etc., oferecem serviços próprios atraindo espaços comerciais em suas atuações. Funcionam em rede (SRNICEK, 2017, p. 30), o que torna ainda mais 
valioso aumentar a quantidade de seus usuários, incrementando a importância da publicidade direcionada, algo típico de bases como a Google, o qual "cria algoritmos de publicidade, não algoritmos de informação" (NOBLE, 2018, p. 28, tradução nossa), enquanto amplia o valor de mercado da plataforma em si mesma.

A dinâmica de controle biopolítico, em que o sujeito é tornado dividual pela transformação da vida em dados compagináveis (DELEUZE, 1992, p. 222), é o que permite condicionamentos mais delicados e menos invasivos, já que senhas ou direcionamentos são visto como menos coercitivos do que a força disciplinar-punitiva. Por óbvio que, embora as práticas de controle estejam em plena operação nas mais diversas áreas, desde consumo a segurança, isso não significa a abolição de instrumentos disciplinares aos indesejáveis e improdutivos ou, ainda, a ausência de processos discriminatórios no interior das novas tecnologias.

Não se pode furtar deste alerta sob pena de incompreensão da própria biopolítica, pois essa "produz subjetividade, ou produz morte, ou torna-se sujeito a seu próprio objeto, ou definitivamente o objetiva. Ou é política da vida ou sobre a vida" (ESPOSITO, 2006, p. 53, tradução nossa). Isso indica que, na ordem neoliberal, o controle é a regra disposta pelas ferramentas tecnológicas e formas de negócio, mas que diante da ruptura produtiva almejada, estarão os sujeitos à mercê das forças disciplinares, ainda plenamente capazes de permitir a morte (FOUCAULT, 2005, p. 287).

Parte do delírio contemporâneo está na ideia de que a ampliação tecnológica comporta a solução de todos os males. Tal postura ignora o manejo de dados desconexos, que um dia terão sentido ou poderão ser associados, mesmo que no momento não o façam, dando a impressão que geram apenas inconvenientes anúncios do Google e Facebook, mas que nada impede de serem igualmente capazes de direcionar uma patrulha policial ou um drone pela mesma atuação, neste caso nas mãos de agências de segurança (MOROZOV, 2018, p. 39).

Porém, torna-se difícil a tarefa da crítica quando há, de forma geral, a incompreensão sobre o modo como esses conteúdos ou dados são utilizados, obtidos, quantificados ou mesmo relacionados com atividades diárias de qualquer um. Apesar disso, qualquer indivíduo que observe aos parâmetros digitais percebe que é rastreado e segmentado em pluralidades de informações/dados por governos e empresas cada dia com mais intensidade, formando verdadeiras caixas pretas de conteúdos sobre cada ser humano (PASQUALE, 2015, p. 3).

Logo, a conclusão sobre o valor contido nos dados/metadados torna-se evidente, somado ao fato indiscutível de que as interconexões hoje somente são possíveis por mecanismos automatizados baseados em cálculos, probabilidades e margens de risco: os chamados algoritmos (PASQUALE, 2015, p. 8). Isso clarifica como operam biopoliticamente dados e metadados através de uma razão algorítmica. Nada melhor para prever os comportamentos humanos do que o próprio sujeito fornecendo, voluntariamente ou não, sua própria dividualização.

Trata-se, metaforicamente, de uma espécie de encarceramento voluntário, no qual o sujeito desde a prisão supõe livremente fornecer dados diários sobre sua vida necessários, exatamente, para fortalecer as amarras que o contém. A seu turno, o modelo de plataformas tecnológicas preza pelo conhecimento como base econômica, e isso significa dados e metadados disponíveis às bases algorítmicas, em especial aqueles que são obtidos e que antes simplesmente não existiam ou não eram considerados pelas empresas que prestavam tais serviços. Por exemplo, a Uber enquanto plataforma consegue facilitar transações, individualizar usuários indesejados e rastrear passageiros e veículos, de modo que esses três elementos pouco têm ligação com o transporte de pessoas, mas trazem à tona uma série de conteúdos antes ignorados (MOROZOV, 2018, p. 59).

A conjugação e manejo de dados por softwares baseados em algoritmos (chamados de inteligência artificial) fazem parte da realidade, o que não elide as simples dúvidas sobre como tais cálculos funcionam, se podem ser influenciados, condicionados, viciados ou mesmo quais os problemas já apresentados. Questionamentos como esses apenas demonstram a amplitude do que se desconhece e, ao mesmo tempo, do quanto se abdica para um sistema que não se compreende e, não raro, esconde seus equívocos podendo provocar danos sociais massivos.

\section{Dados e Manipulações: algoritmos a serviço da pós-democracia}

Não se precisa perquirir demasiadamente sobre as questões levantadas até agora para se perceber a necessidade de acompanhamento das atividades empresariais que envolvem dados ou metadados. Embora muitas das atividades desempenhadas por essas empresas sejam definidas como monopólios, caso emblemático da Amazon, as legislações antitrust ${ }^{l}$ ou inexistem ou, como mais se costuma notar, não incidem sobre estes conglomerados. Esse tipo de atuação não surpreende, tendo em vista que a lei, não raro, funciona como tática de controle e não apenas como mero instrumento de soberania (FOUCAULT, 2008, p. 132).

Portanto, o recurso a legislações ou atuações estatais normalmente nubla o fato da profunda cumplicidade dos estratos empresariais com as dinâmicas estatais e seus lobbies. Entes públicos e corporações atuam em mútuo benefício e gerenciam conjuntamente os negócios dataficados na direção do seu caminho mais 
produtivo em termos neoliberais. Até mesmo porque, a partir do uso de algoritmos, basta pensar em problemas de criminalidade e segurança, para se antever que o mais importante são as margens de risco, e não necessariamente a solução dessas questões (CHIGNOLA, 2018, p. 256).

Assim, compreender os algoritmos e os riscos neles envolvidos, especialmente na adoção acrítica da tecnologia como sinal de progresso, é uma espiral que enclausura a todos numa visão romântica da neutralidade dos cálculos matemáticos e dos sujeitos envolvidos com tais criações. De outro modo, abrir-se a esse tipo de abordagem faz com que se possa perceber o quanto as estratégias envolvidas com a lógica algorítmica reproduzem mecanismos ostensivamente racistas, sexistas ou mergulhados em distorcidos ideais de meritocracia, conforme já amplamente confirmado por pesquisas no Vale do Silício (NOBLE, 2018, p. 10).

Portanto, alguns modelos de algoritmos apenas servem para maximizar tecnologicamente as discriminações e desigualdades produzidas por uma sociedade com uma radical desigualdade. Exemplo disso pode-se perceber quando se examina, no caso do sistema penal, um teste usualmente aplicado para medições de risco de reincidência de apenados (LSI-R - Level of Service Inventory-Revised), onde um dos padrões centrais de questionamento passa por se saber quando, pela primeira vez, o sujeito teve um envolvimento com as forças policiais, concluindo-se que maior será o risco de reincidência quanto mais cedo esta variável aparecer. Ninguém ignora - ou não deveria, senão de modo cínico - a seletividade profunda de exercício do poder punitivo que faz com que, principalmente homens negros e latinos (mormente no contexto norte-americano), sejam parados e revistados desde a juventude, muito mais vezes do que homens brancos (isso sem levar em consideração os bairros e outras questões criminológicas relacionadas a cidades) (O’NEIL, 2017, p. 15).

Abandonar a pretensa neutralidade tecnológica dos algoritmos, observando seus problemas e pressupostos, intrínseca à composição de seus programas, é tão relevante quanto entender as fórmulas dos cálculos. Comumente acredita-se que mecanismos de busca e outros dispositivos baseados em inteligência artificial (algoritmos) são elaborados tendo em vista apenas filtros de personalização, ou seja, que seriam aperfeiçoados e aprimorados para cada indivíduo, de acordo com os resultados coletados pelo perfil dos usuários (PARISER, 2012, p. 7-11), de maneira que seus criadores não teriam qualquer influência nos resultados produzidos.

Esse talvez seja um dos maiores engodos embutidos nos ditos sistemas inteligentes, que se dispõem à previsibilidade futura e são baseados em matrizes discriminatórias como reflexo, nada neutro, das relações de poder que as orienta. Veja-se, por exemplo, o mais que generalizado algoritmo de busca da Google, o qual, apesar de louvado, até meados de 2012, ao referir à pesquisa sobre mulheres negras, latinas e asiáticas, imediatamente, remetia a estereótipos sexualizados, apresentando como resultados primários páginas pornográficas. (NOBLE, 2018, p. 11).

Os erros (glitch) desses mecanismos de busca e outros instrumentos são geralmente atenuados, ignorando-se a opressão que os algoritmos exercem. Não obstante, como justificar que, da mesma forma, em 2015, o dispositivo de reconhecimento facial da Google indicava macacos e animais como primeiro resultado para afro-americanos, ou ainda, que a busca por nigger house (com significado racista) indicasse a Casa Branca durante a administração Obama? Nada estranho que, quando campanhas revelam a existência de resultados sexistas ou racistas em mecanismos de busca, a resposta padrão adotada seja de que isso em realidade ainda seria um espelho dos usuários, o que não se duvida, todavia, também não deve elidir o conglomerado de suas responsabilidades sobre a veiculação e propagação do conteúdo. Em resumo, ignoram-se os algoritmos planificados, direcionando-se a responsabilidade, ao estilo neoliberal, à própria pessoa, responsável por todo e qualquer mal lançado sobre ele (NOBLE, 2018, p. 12-16).

Atente-se que os erros de cálculo estão disseminados pelos dispositivos inteligentes, pois mecanismos de busca, localizadores e instrumentos biométricos funcionam em conjunto (mapeamento em rede) na tentativa de predizer comportamentos e conduzir às respostas desejadas pelos detentores dessas ferramentas biopolíticas (AMOORE, 2013, p. 41). Por outro lado, cabe referir que muitas vezes as predileções ou projeções se baseiam na ausência de dados ou metadados, de modo que a falta de informação precisa é registrada como um demérito sistêmico que também é interpretado como um risco (CHIGNOLA, 2018, p. 259). Por esses motivos é que a indagação sobre os critérios de algoritmos impostos atualmente é tão valiosa, conforme realiza Pasquale (2015, p. 9). O autor, ao questionar tais fatores, almeja evitar que o uso de instrumentos disciplinares ou de controle reduzam sujeitos ao paradigma kafkiano, em que não se sabe o que ocorre e ainda assim se está à mercê de sanções que se desconhece.

Frise-se o fato de que tais (ab)usos realizados por essas corporações ou mesmo Estados simplesmente não possuem qualquer espécie de vedação ou sanção (não se tratam de ações criminosas ou mesmo de rupturas democráticas), o que significa que a produção de danos sociais massivos (BARAK, 2015) não passa de mais um "erro/glitch" em nome do progresso neoliberal. Diante da dimensão de danos produzidos é que a autora O'Neil (2017, p. 16) intitulou os modelos estatísticos criados como o LDI-R em "armas de destruição matemáticas" (analogicamente à noção de "armas de destruição em massa" - e contando com as mesmas 
iniciais em inglês - WMDs), criando processos de loops com seus feedbacks, e que geram círculos viciosos no sentido de que as suposições do modelo são apenas reforçadas pelos cálculos de previsão futura.

Percebe-se que alguns ambientes são utilizados como laboratórios para os testes com algoritmos, e esses modelos devidamente experimentados podem ser expostos a novos indivíduos e com novas funções, para assim aumentar a eficiência de qualquer elemento desejado pelo modelo neoliberal, em que tudo e todos são reduzidos a dados contabilizáveis e vendáveis. Estabelece-se, assim, uma governamentalidade algorítmica, com a multiplicação de táticas complexas de exercício de poder sobre as populações (FOUCAULT, 2008, p. 143), executadas simbioticamente por Estados e corporações transnacionais.

Nesse modelo, tudo é reduzido ao plano individual, de modo que as mazelas sociais antes combatidas ou pretensamente redutíveis desde um welfare state, agora são condicionadas a mudanças e transformações pessoais fomentadas por padrões de retroalimentação. Dito de outra maneira, do mesmo modo que um filtro de spam aperfeiçoa seus mecanismos com cada usuário, esse modelo estatal pretende a melhoria dos cidadãos como forma de aumentar a sua efetividade e, por conseguinte, reduzindo custos enquanto monitora cada vez mais as suas ações e padrões (reduzidos a dados) (MOROZOV, 2018, p. 96). Isso se reflete em desarticulações ou eliminações de organismos e responsabilidades tipicamente estatais em sociedades democráticas, sendo projetado para a população a responsabilidade de atuar em prol de seu próprio desenvolvimento e na desoneração pública (atendendo aos interesses do mercado), sempre buscando a maximização da eficiência neoliberal aplicada à gestão humana.

Se os reflexos dessas dinâmicas não podem ser isolados localmente, pois comportam uma escala global, suas nuances em termos de realidade nacional ganham um colorido especial de análise. Logo, os auspícios neoliberais também ditados tecnologicamente, com especial atenção ao gerenciamento dados, devem ser examinados desde o contexto brasileiro. A especificidade em termos locais passa, como aponta Casara (2018, p. 16-17), pela incidência em maior grau de instrumentos repressivos, marcas típicas de Estados Pós-Democráticos.

Os contornos desse tipo de condição dispõem uma espécie de fachada formal democrática, pronta a encobrir as decisões políticas sob outra instância, não raro programadas por plataformas de corporações, mercados, agências de risco, dentre outros inúmeros agentes disformes que administram os rumos do dito progresso neoliberal enquanto reduzem as relações ao fator mercadológico e à responsabilização empreendedora do sujeito.

Portanto, a biopolítica imposta enquanto gestão da vida (BAZZICALUPO, 2017, p. 17) em prol dos interesses do mercado está longe de ser incompreensível, não obstante deva ser vista com atenção, porque se utiliza da liberdade individual, incrementada tecnologicamente e combinada a processos alienantes dos fundamentos básicos de democracia. No caso brasileiro, a perspectiva se agrava tendo em vista o tradicional poder de morte que é exercido quase de maneira naturalizada, espécie daquilo que Mbembe chama de "necropolítica" (2017, p. 65). Não seria inviável afirmar que um traço autoritário brasileiro bem localizado nas práticas escravocratas pouco assumidas é multiplicado num modo neoliberal de vida, razão, não raro, da

crença em resposta de força, medo e desconfiança [...], tendência a agredir indivíduos desviantes dos valores convencionais, oposição ao que é da ordem subjetiva/sensível, disposição a pensar mediante categorias rígidas (estereótipos), identificação com figuras de poder e hostilidade generalizada (CASARA, 2018, p. 73).

Assim, essas novas tecnologias dispostas num contexto de pura vulnerabilização social, como no caso brasileiro, aprofundam um governo dos corpos dirigido a maximizar a morte. O controle da população conectada indelevelmente em plataformas digitais, cada dia mais quantificada, calculada e reduzida a dados passíveis de negociação e manejo de algoritmos, e coligada à atuação do poder punitivo estatal sobre aqueles considerados inúteis aos ganhos econômicos ou considerados desviantes das proposições dessa sociedade, pode bem indicar o cenário futuro a ser vivido por todos.

Nesse sentido, importante retomar a crítica desses instrumentos de cálculo e metrificação da vida sejam softwares, Inteligências Artificiais (IAs) -, pois são os próprios meios propostos a quase anular o diálogo em favor de narrativas unidimensionais, trocar a feição dos cidadãos pela de consumidores, numa política muito pouco interessada no comum e mais afeita aos atos de governo como produto de marketing, panorama nefasto ao desenvolvimento das complexas democracias contemporâneas. Destarte, as bases tecnológicas que antes são parâmetros políticos camuflados de neutralidade, usam sua pretensa objetividade para influir decisivamente nas democracias (MOROZOV, 2018, p. 142).

A política que coloca a IA no centro de suas operações nos promete perfeição e racionalidade. Ao fazer isso, contudo, ela aplaina a imensa complexidade das relações humanas, simplificando narrativas complexas em regras algorítmicas concisas e explicações monocausais. Enquanto a nossa experiência fenomenológica do mundo não se conformar aos modelos simplistas por trás da maioria dos sistemas de IA, não deveríamos 
nos surpreender ao ver mais e mais pessoas caindo nas narrativas conspiratórias e extremamente complexas das fake news: as notícias podem ser completamente falsas, mas, pelo menos, admitem uma complexidade narrativa irreconhecível por Alexa ou Siri (MOROZOV, 2018, p. 142-143).

Por mais que Morin e Le Moigne (1999, p. 26) tenham delimitado há muito tempo a necessidade de inserir a complexidade nos debates dos problemas enfrentados pela humanidade, o que se apresenta, na contramão, é a ode à simplificação. Não somente pelo quadro tecnológico capitalista que segmenta o pensamento em partes quantificáveis (e lucrativas), plenamente assimilado por cada um dos seres humanos empresários de si, mas também pelo retrato patológico de uma população absorvida por smartphones, redes sociais, dados, IAs e algoritmos, e que ao mesmo tempo nutre ódio ao pensamento, pois planifica e reproduz sua (falta de) reflexão através da transparência digital tão bem vista nas chamadas fake news, o efeito rebote não dista do reforço da punição extrema como ordem naturalizada no cotidiano de todos.

Figura disso pôde ser comprovada tão fortemente, talvez como em poucos momentos da história brasileira, no último processo eleitoral em 2018, em que restou comprovado que $90 \%$ dos eleitores do então candidato a Presidente, Jair Bolsonaro, acreditaram em fake news (PAQUINI, 2018) provenientes de redes sociais como o Facebook e Twitter, o que demonstra que a construção, adulteração ou manipulação da verdade (pósverdade) (KEYES, 2004, p. 12-13) não é algo considerado reprovável, desde que proponha uma narrativa simples e capaz de satisfazer seus desejos. Própria atualmente do ambiente pós-democrático nacional, o falseamento não é mais considerado um valor relevante, pois "na pós-democracia, inimigo é todo aquele que não possui valor de uso dentro da racionalidade neoliberal” (CASARA, 2018, p. 75). Caso a isso haja oposição, sempre emergirá a figura do inimigo interno, também canalizado tecnologicamente.

A influência de plataformas algorítmicas e outros instrumentos tecnológicos tem ganho terreno no exercício de controle de indesejáveis que diluir em teorias da conspiração já soa ridículo: repita-se, as variações racistas, sexistas e discriminatórias (NOBLE, 2018) de buscas ou a notória influência nas eleições norte-americanas (HOWARD et al., 2017; HOWARD; KOLLANYI; WOOLLEY, 2016), e mesmo no Brasil com a proliferação de notícias falsas e bots atuando maciçamente nas redes sociais, são apenas a expressão muito reduzida de suas performances. Lembra-se, por exemplo, os ataques virtuais ao jornal Folha de São Paulo, ainda no final de 2018, quando bots inundaram com discursos de ódio publicações sem nenhum vínculo político ou eleitoral (os anúncios tratavam de joias e um dono de boteco famoso), tendo sido ativados por palavras-chave, no caso específico bolovo e bolso - em referência/defesa ao então candidato à presidência da República (TUÍTES..., 2018).

O cenário nacional, portanto, de um projeto neoliberal que dispõe biopoliticamente um governo de si e dos outros desde dinâmicas tecnológicas necessita de permanente reflexão. Todavia, o que não fica claro para a maior parte da população é que isso somente é possível diante da inflexão, da instigação, da suposta otimização da liberdade através do fornecimento de dados voluntariamente, transformando-a em fomentadores do próprio espetáculo simplista, por vezes carregados de autoritarismo e ódio, que a vitimiza.

Os termos radicais com que se confronta diante desse quadro, por sua vez, acabam por esgotar as energias vitais dos sujeitos, inclusive para se perceberam violentados com tal ambiente, ademais de, no caso brasileiro, gerar demandas de crescente indiferença à solidariedade e a multiplicação de bodes expiatórios às agruras nacionais. Têm-se, assim, a montagem de uma necropolítica com requintes futuristas.

\section{Considerações finais}

O quadro contextual traçado neste estudo não tem qualquer pretensão de definição estrita ou esgotamento temático, porém almeja, de alguma forma, atender aos anseios de uma compreensão sobre fatos que acometem a realidade nacional em termos de controle de dados numa sociedade democrática. Para tanto, tornou-se forçoso delinear as tecnologias biopolíticas contemporâneas voltadas ao controle, sem, contudo, deixar de atentar para as estratégias disciplinares e soberanas reconfiguradas contra aqueles considerados inaptos ao modo de vida neoliberal.

Com base na percepção de que os modos de exercícios de poder biopolítico encontram-se multiplicados e disseminados socialmente, sendo incidentes desde pontos variáveis, sobretudo quando inexistem distinções entre agentes públicos ou privados em tal contexto, pôs-se em xeque a leitura comum e unidimensional dos usos tecnológicos como panaceia geral, inclusive aos tradicionais problemas sociais enfrentados. A simples observação histórica de que dispositivos tecnológicos vêm tendencialmente servindo aos propósitos da governamentalidade capitalista seria suficiente para se consolidar um alerta sobre a questão, entretanto, isso ainda se agrava pelo fato de que dados e metadados de cada indivíduo humano adquiriram no capitalismo tecnológico valores e relações próprias, pautando novas formas de quantificação, metrificação e comercialização da vida. 
A partir disso, torna-se necessário refutar o senso comum que atrela o uso de tecnologias, em ambiente mercadológico, a uma suposta neutralidade e a atribuição de seus erros a meros equívocos operacionais. Afastar os vícios de compreensão não é apenas uma tarefa específica de apreciação, principalmente em termos nacionais, mas um esforço nuclear para o desvelamento dos generalizados projetos neoliberais de controle de populações.

As dinâmicas do uso variado dos dados/metadados demonstram como reverberam na proliferação da vulnerabilização humana como parte das mercadorias a serem capitalizadas, sempre em busca de aumento da lucratividade. Portanto, ao se questionar acerca dos reflexos próximos e imediatos de uma sociedade do controle no Brasil, consegue-se observar que a tecnologia e a liberdade, perfectibilizadas desde um big data, já aparece ocupando um ponto de destaque na execução dos projetos políticos neoliberais implementados no País. Todavia, nos estertores de um Estado Pós-Democrático, que o Brasil dá sinais, existem os aprofundamentos autoritários gerados pela profusão falseada de discursos de ódio que reforçam dinâmicas de morte tradicionalmente exercidas.

Nesses termos, diante disso, o governo da vida desde um modo neoliberal de existência, amparado tecnologicamente, produz relações sociais patológicas e esgotadas em afetos concorrenciais, ao mesmo tempo que naturaliza a otimização da liberdade em favor das plataformas de controle que gerirá sua própria aniquilação.

\section{Referências}

AMOORE, L. The politics of possibility: risk and Security beyond probability. London, United Kingdom: Duke University Presse, 2013. BARAK, G. Os crimes dos poderosos e a globalização do crime. Revista Brasileira de Direito, Passo Fundo, v. 11, n. 2, p. 104-114, dez. 2015. Disponível em: https://seer.imed.edu.br/index.php/revistadedireito/article/view/931. Acesso em: 13 abr. 2020.

BAZZICALUPO, L. Biopolítica: un mapa conceptual. São Leopoldo, Porto Alegre: Unisinos, 2017.

CASARA, R. R. R. Estado pós-democrático: neo-obscurantismo e gestão dos indesejáveis. Rio de Janeiro: Civilização Brasileira, 2018. CHIGNOLA, S. A vida, o trabalho, a linguagem: biopolítica e biocapitalismo. Cadernos IHU, nº. 228, v. 13, p. 3-19, 2015.

CHIGNOLA. A toupeira e a serpente. Revista de Direitos e Garantias Fundamentais, v. 19, n. 3, p. 239-269, 2018.

DELEUZE, G. 'Post-scriptum' sobre as sociedades de controle. Conversações. São Paulo: Editora 34, n. 1, 1992.

ESPOSITO, R. Bíos: Biopolitica y filosofia. Buenos Aires: Amorrortu, 2006.

EUROPEAN COMMISSION. Competition: Antitrust. Disponível em: http://ec.europa.eu/competition/antitrust/overview_en.html. Acesso em: 04 maio 2019.

FIDELIS, A. L. Entre o "laissez-faire" americano e o "intervencionismo" europeu: para qual direção aponta a investigação do CADE sobre o mecanismo de busca do Google. Revista de Defesa da Concorrência: v. 3, n. 2, p. 65-86, 2015.

FOUCAULT, M. Em defesa da sociedade. São Paulo: Martins Fontes, 2005.

FOUCAULT, M. O Sujeito e o Poder. In: DREYFUS, H. L.; RABINOW, P. Michel Foucault: uma trajetória filosófica: para além do estruturalismo e da hermenêutica. Rio de Janeiro: Forense Universitária, 1995.

FOUCAUlT, M. Segurança, Território, População: Curso do Collège de France (1977-1978). São Paulo: Martins Fontes, 2008.

GOOGLE é multado em US\$ 56,8 milhões por violar lei de proteção de dados na Europa. O Globo, Rio de Janeiro, 21 jan. 2019. Disponível em: https://oglobo.globo.com/economia/tecnologia/google-multado-em-us-568-milhoes-por-violar-lei-de-protecao-de-dadosna-europa-23389682. Acesso em: 4 maio 2019.

HAN, B. Sociedade do cansaço. Petrópolis, RJ: Vozes, 2015.

HONESKO, V. N. Sobre o governo do real: a vida nos domínios do capitalismo informacional. Profanações, [Paraná], n. 1, p. 24-38, jul. 2018. HOWARD, P N. et al. Junk news and bots during the US election: What were Michigan voters sharing over Twitter. Computational Propaganda Research Project, Oxford Internet Institute, Data Memo, n. 2017.1, p. 1-5, 2017.

HOWARD, PN.; KOLLANYI, B.; WOOLLEY, S. Bots and Automation over Twitter during the US Election. Computational Propaganda Project: Working Paper Series, 2016.

KEYES, R. The Post-Truth Era: dishonesty and deception in contemporary life. New York, United States: St. Martin Press, 2004. MBEMBE, A. Políticas da inimizade. Lisboa, Portugal: Antígona, 2017.

MORIN, E.; LE MOIGNE, J. L'intelligence de la complexité. Montreal, Canada: L'Harmattan 1999.

MOROZOV, E. Big tech: a ascensão dos dados e a morte da política. São Paulo: Ubu, 2018.

NOBLE, S. U. Algorithms of oppression: how search engines reinforce racism. New York, United States: New York University Press, 2018.

O'NEIL, C. Weapons of math destruction: how big data increases inequality and threatens democracy. United States: Broadway Books, 2017.

PAQUINI, P. Estudo diz que 90\% dos eleitores de Bolsonaro acreditaram em fake news. Valor Econômico, São Paulo, 2 nov. 2018. Disponível em: https://valor.globo.com/politica/noticia/2018/11/02/estudo-diz-que-90-dos-eleitores-de-bolsonaro-acreditaram-em-fakenews.ghtml. Acesso em: 9 abr. 2020.

PARISER, E. O filtro invisivel: o que a Internet está escondendo de você. Rio de Janeiro: Zahar, 2012. 
PASQUALE, F. The black box society: the secret algorithms that control money and information. Cambridge, United States: Harvard University Press, 2015.

REVEL, J. Foucault, un pensamiento de lo discontínuo. Buenos Aires, Argentina: Amorrortu, 2014.

SRNICEK, N. Plataform capitalism. Cambridge, United States: Polity Press, 2017.

TUÍTES da Folha sobre "bolso" e "bolovo" ativam ação de robôs, que saem em defesa de Bolsonaro. Revista Fórum, Porto Alegre, 25 out. 2018. Disponível em: https://revistaforum.com.br/politica/tuites-da-folha-sobre-bolso-e-bolovo-ativam-acao-de-robos-que-saemem-defesa-de-bolsonaro/. Acesso em: 4 mar. 2019.

\section{Nota}

1 As legislações antitruste têm como escopo evitar a formação de monopólios, conglomerados, ou analisando fusões, seguindo a ideia de preservar a concorrência, regulando o poder do mercado. Nesse sentido, cabe mencionar que a postura dos Estados Unidos a respeito do assunto fomenta formações como a da Amazon, ao menos essaé a conclusão das análises da legislação norte-americana, a qual se baseia na Seção 2 do Sherman Act, onde se verifica a atuação de Cortes de forma permissiva e condescendente com o setor privado (FIDELIS, 2015, p. 69-70). Em comparação a legislação em vigor na União Europeia tem bases mais rígidas e vem atuando de forma mais dura sobre tais temas, tendo como base os artigos 101 e 102 do Treaty on the Functioning of the European Union (EUROPEAN COMMISSION, 2019), bastando a verificação de recentes multas sobre empresas ligadas à tecnologia como o caso do Google, com base em novas regulamentações do ano de 2018, de modo que as bases antitrustes europeias apresentam-se em constante mutação com tais regulações, a fim de adaptar-se às novas dinâmicas capitalistas (GOOGLE..., 2019).

\section{Augusto Jobim do Amaral}

guto_jobim@hotmail.com

Doutor em Altos Estudos Contemporâneos pela Universidade de Coimbra (UC)

Doutor, Mestre e Especialista em Ciências Criminais pela Pontifícia Universidade Católica do Rio Grande do Sul (PUCRS)

Professor do Programa de Pós-Graduação em Ciências Criminais da PUCRS

\section{PUCRS}

Av. Ipiranga, 668, Partenon

Porto Alegre - RS - Brasil

CEP: 90619-900

\section{Felipe da Veiga Dias}

felipevdias@gmail.com

Doutor em Direito pela Universidade de Santa Cruz do Sul (UNISC)

Professor do Programa de Pós-Graduação em Direito da Faculdade Meridional (IMED)

\section{IMED}

Rua Senador Pinheiro, 304, Rodrigues

Passo Fundo - RS - Brasil

CEP: 99070-220

\section{Agradecimentos \\ Não se aplica. \\ Agência financiadora \\ Não se aplica.}

\section{Contribuições dos autores}

O texto foi produzido, por completo, com a participação dos dois autores.

\author{
Aprovação por Comitê de Ética e consentimento para parti- \\ cipação \\ Não se aplica.

\section{Consentimento para publicação} \\ Os autores consentem com a publicação e a cessão de direitos \\ autorais a publicação.
}

Conflito de interesses

Não há conflito de interesses. 